\title{
Water institutional reforms: theory and practice
}

\author{
R. Maria Saleth ${ }^{\mathrm{a}}$ and Ariel Dinar ${ }^{\mathrm{b}}$ \\ ${ }^{a}$ Corresponding author. International Water Management Institute, PO Box: 2045, Colombo, Sri Lanka. \\ Fax:0094-11-2786854.E-mail: r.saleth@cgiar.org \\ ${ }^{b}$ The World Bank, 1818-H Street, NW, Washington, DC 20433, USA \\ Received 2 November 2004; accepted in revised form 2 November 2004
}

\begin{abstract}
This paper aims to set the stage with an outline of the conceptual, analytical and theoretical aspects of water institutional reforms and a synthesis of the main findings from the reform experiences of six countries: Australia, Chile, Morocco, Namibia, South Africa and Sri Lanka. Utilizing the latest developments in the literature on the subject, this paper presents the analytics of unbundling water institutions to show their endogenous and exogenous linkages, the transaction cost approach as a diagnostic framework for understanding the role of factors affecting water institutions, and a stage-based perspective to provide insights into the internal mechanics and dynamics evident in the process of water institutional change. Using this analytical framework and theoretical approach, this paper also identifies a few practically relevant principles for reform design and implementation. Based on a review of country reform experiences, the paper also synthesizes reform theories with actual practices by providing anecdotal evidence for various theoretical postulates and practical reform principles.
\end{abstract}

Keywords: Australia; Chile; Institutional environment; Institutional packaging; Institutional sequencing; Institutional structure; Morocco; Namibia; Political economy; South Africa; Sri Lanka; Subjective theory; Theories of institutional change; Transaction cost approach; Water institutional change; Water sector reform

\section{Introduction}

The institutional arrangements governing the water sector are undergoing remarkable changes in many countries around the world. Such changes, which have been observed, especially during the past decade or so, are due more to purposive reform programs than to the normal process of institutional evolution. Water institutional arrangements and their change process are well documented with varying details, contexts and perspectives (e.g. Le Moigne et al., 1992; 
Vermillion, 1997; Easter et al., 1998; Savedoff \& Spiller, 1999; Challen, 2000; Shirely, 2002; Dinar, 2000; Saleth \& Dinar, 1999, 2000; Gopalakrishnan et al., 2004). While the literature is as rich and diverse as the country experiences, it still lacks attempts at a systematic application of institutional economics theories to understand and evaluate the ongoing process of water institutional reforms. Recently, Saleth \& Dinar (2004) have made an attempt in this direction by building on the institutional economics literature (e.g. Williamson, 1985; Bromley, 1989a; North, 1990a and b; Ostrom, 1990) and doing a cross-country analysis of water institutional reforms in 43 countries/regions. This special issue brings together a set of papers that contrast this recent attempt with existing literature and reflect its relevance for explaining the ongoing reform process in country-specific contexts. ${ }^{1}$

Of the eight papers included in this special issue, the present one and that by Livingston deal with the theoretical and methodological issues surrounding water institutions and their change process. The other papers by Mckay, Hearne and Donoso, Doukkali, Heyns, Backeberg and Samad review respectively the water institutional reforms in Australia, Chile, Morocco, Namibia, South Africa and Sri Lanka in the light of reform theories and policy prescriptions. As such, these papers provide anecdotal evidence for the practical relevance of theoretical postulates and reform principles. Since these papers, taken together, integrate the theoretical and methodological issues with the practical and operational aspects of water institutional reforms in a diverse setting and perspective, this special issue can provide very valuable insights on the interface between the theory and practice of water institutional reforms. This paper sets the stage for this special issue with an outline of the theoretical aspects of water institutional reforms and an interpretative summary and synthesis of the main findings from country reform experiences.

\section{Water institutions: structure and environment}

Following the general definition of institutions (see Bromley, 1989a; North, 1990a; Ostrom, 1990), water institutions can be defined as rules that together describe action situations, delineate action sets, provide incentives and determine outcomes both in individual and collective decisions related to water development, allocation, use and management. Like all institutions, water institutions are also subjective, ${ }^{2}$ path dependent, ${ }^{3}$ hierarchical and nested both structurally and spatially and embedded within the cultural, social, economic and political context. These features, taken together, suggest (a) individuals and their perception as a source of change, (b) the continuous and gradual nature of the change process, (c) the scope for scale economies in

\footnotetext{
${ }^{1}$ These papers were originally presented in the learning workshop organized as part of the 25th Conference of the International Association of Agricultural Economists held in Durban, South Africa during August 16-22, 2003.

${ }^{2}$ Institutions are subjective in origin and operation but objective in manifestation and impact (Hodgson, 1998). Their subjective nature is recognized as the "belief system" (Veblen, 1919), "behavioral habits" (Commons, 1934), "mental construct" or the "subjective model" of individuals (North, 1990a) and "artifacts" that think and act through the human medium (Douglas, 1986; Stein, 1997; Ostrom, 1999).

${ }^{3}$ Path dependency means that the present status and future direction of institutions cannot be divorced from their earlier course and past history (North, 1990a).
} 
transaction costs and increasing returns in institutional performance, and (d) the powerful role of contextual factors in institutional change. Thus, institutional change can emerge both from the endogenous structure as well as from the exogenous environment of institutions.

From an analytical and methodological perspective, the institutional features noted above also have major but somewhat less understood implications. For instance, since the institutional features are nothing but different forms of institutional linkages, they have major roles in institutional transaction and performance. ${ }^{4}$ But, such impacts, though recognized well in the literature, are not formally incorporated within the transaction cost theory. The institutional features also establish a close resemblance between an institutional system and an ecosystem allowing the development of the institutional ecology principle. ${ }^{5}$ Saleth \& Dinar (2004) have used this principle as a conceptual basis for developing the institutional decomposition and analysis (IDA) framework useful for unbundling institutions in general and water institutions in particular. For instance, water institutions can be broken down into institutional structure (governance structure) and institutional environment (governance framework). Similarly, the institutional structure can be decomposed into its legal, policy and organizational components, which can, in turn, be broken down further to highlight their underlying institutional aspects. The unbundling exercise within the IDA framework is, therefore, very valuable for evaluating the internal and external linkages of water institutions.

The internal linkages and dynamics within water institutions can be understood with an illustrative unbundling of water institutional structure as depicted in Fig. 1. Although this figure is largely self-explanatory, a few aspects require attention. The overall performance of water institutions depends not only on the capabilities of their individual aspects but also on the strength of structural and functional linkages between them. The arrows in Fig. 1 indicate an illustrative set of linkages that are possible both within and across the three institutional components. Some of these linkages are direct and immediate while others are indirect and remote. Similarly, some institutional components have more and diverse effects while others have limited effects. An evaluation of these linkages and the institutional channels through which their impacts are conveyed are very valuable for developing reform design and implementation principles.

Since the institution-performance interaction in the context of water occurs within an environment characterized by the interactive role of many factors outside the strict confines of both the water institutions and the water sector, institutional linkages and their performance implications are also subject to exogenous and contextual influences. These effects can be formally traced by unbundling the water institutional structure from its institutional environment as shown in Fig. 2. Although the water institutional environment characterized in Fig. 2 is only partial, it can still conceptualize the pathways through which some of major contextual factors can influence institutional performance and change. Looking at the two analytical segments in Fig. 2, the first segment captures the interaction between water institutions and sector performance and the other captures the general environment within which such interaction occurs. Fig. 2 also contrasts the

\footnotetext{
${ }^{4}$ That is, path dependency means institutional linkages in a temporal sense. Similarly, the hierarchical, nested and embedded nature of institutions means institutional linkages in a structural sense.

${ }^{5}$ While this principle seems trivial, it is powerful not only as a pedagogic tool to present institutions to the public and policy makers but also as a framework to resolve the "evolutionary-equilibrium" conflict in institutional economics (Saleth \& Dinar, 2004).
} 


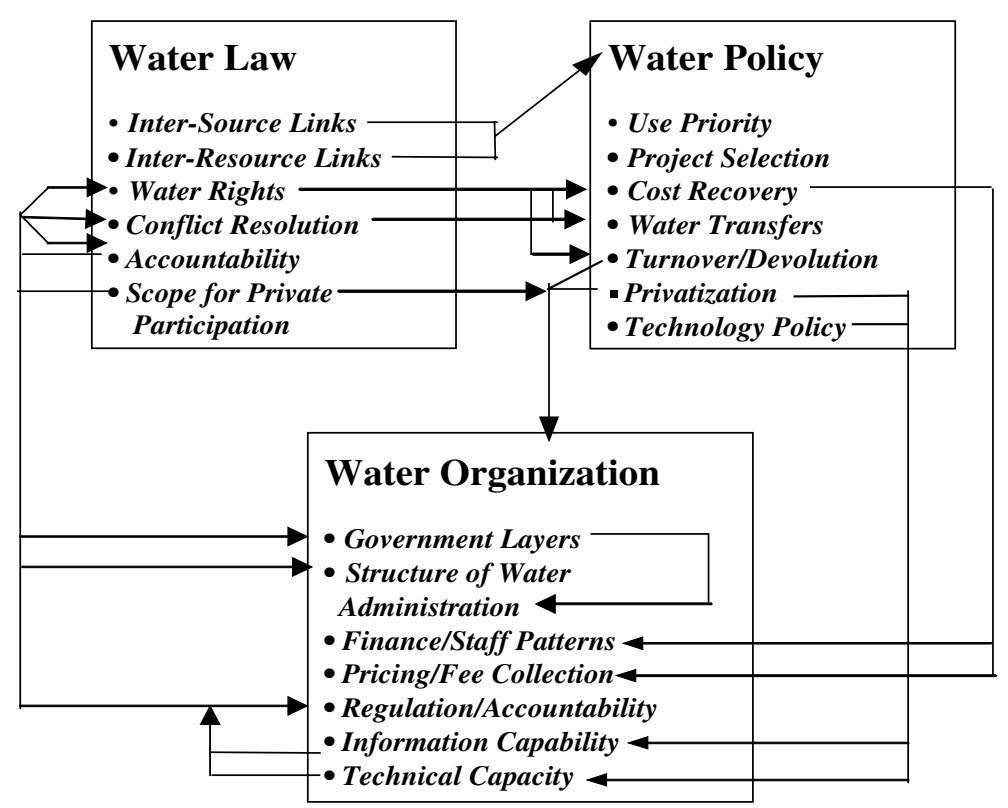

Fig. 1. Water institutional structure: a simplified representation. Source: Saleth \& Dinar (2004).

narrow approach to institutional change focused exclusively on institution-performance interaction with a broader approach focused, not only on such interaction and its larger institutional context, but also on the internal dynamics within water institutions. This allows us to approach water institutional changes from broader institutional economics and political economy perspectives.

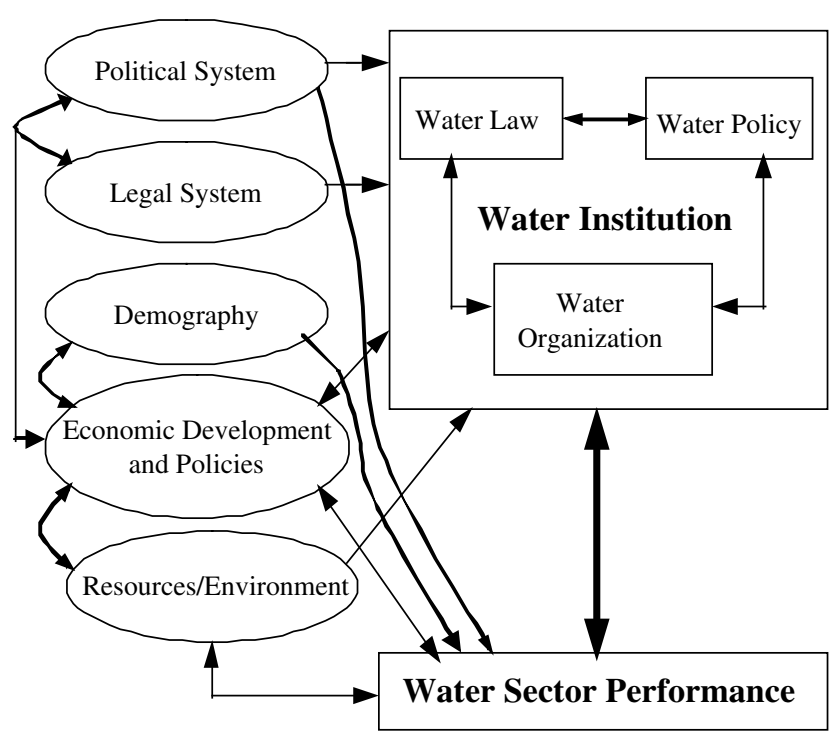

Fig. 2. Water institutional environment: a partial representation. Source: Saleth \& Dinar (2004). 


\section{Institutional transaction cost theory}

With an understanding of the structure and environment of water institutions, it is easier to identify the factors that can affect water institutional change in different contexts. But, it is not that clear how and in what forms these factors influence the change process. The institutional transaction cost theory - as generalized by North (1990a and b) to include non-economic factors and amended further by Saleth \& Dinar (2004) to include the performance and transaction cost impacts of institutional linkages - can be used as a diagnostic framework to interpret the way different factors affect the change process. Broadly, these factors can be grouped into (a) endogenous factors that are internal to the water sector (e.g. water scarcity, water conflicts, financial and physical crisis) and the water institutions (i.e. institutional linkages) and (b) exogenous factors that are outside the strict confines of both the water sector and its institutions (e.g. economic development, demographic growth, technical progress, economic and political reforms, international commitments and natural disasters).

Since the exogenous and endogenous factors are interrelated and their relative impacts differ by context, it is difficult either to isolate their individual roles or to generalize the direction of their effects. But, these effects can be tracked by conceptualizing them as part of either the transaction costs or the opportunity costs of institutional change. The transaction costs cover both the real and monetary costs of altering the regulatory, monitoring and enforcement mechanisms related to water development, allocation and management. These costs are subject to scale economy effects from institutional linkages as well as to the negative (or even positive) effects from path dependency aspects. Similarly, the opportunity costs cover both the real and economic value of opportunities foregone, which, in fact, represent the net social costs of the status quo. The opportunity and transaction costs of institutional changes are not static but change continuously owing to the effects of factors both endogenous and exogenous to the water sector and the water institutions. ${ }^{6}$ There are also intricate linkages between the transaction costs of earlier reforms and those of subsequent reforms. ${ }^{7}$ While it is possible to estimate these costs and benefits in ex-ante and ex-post contexts using both quantitative and qualitative information, the framework is equally valuable as a diagnostic tool in understanding the individual and joint effects of various factors affecting the process of water institutional change (Saleth \& Dinar, 2004).

\section{Water institutional change: a stage-based perspective}

While the institutional transaction cost approach explains the logic of institutional change, it has an analytical limitation in explaining the process of change, as the interesting dynamics are subsumed within the benefit-cost calculus. Other theories such as those based on market approach,

\footnotetext{
${ }^{6}$ For instance, as water scarcity becomes acute, the social costs of inefficient institutions tend to rise. Similarly, these costs are relatively high in the early stages of reform, but tend to decline as institutions mature, with the articulation of stronger institutional linkages to facilitate upstream and downstream changes.

${ }^{7}$ For instance, with transferable water rights, the prospects for conflict resolution and water markets become brighter owing to transaction cost linkages within these aspects. Scale economies in transaction costs are also possible when water reforms form part of larger economic and political reforms.
} 


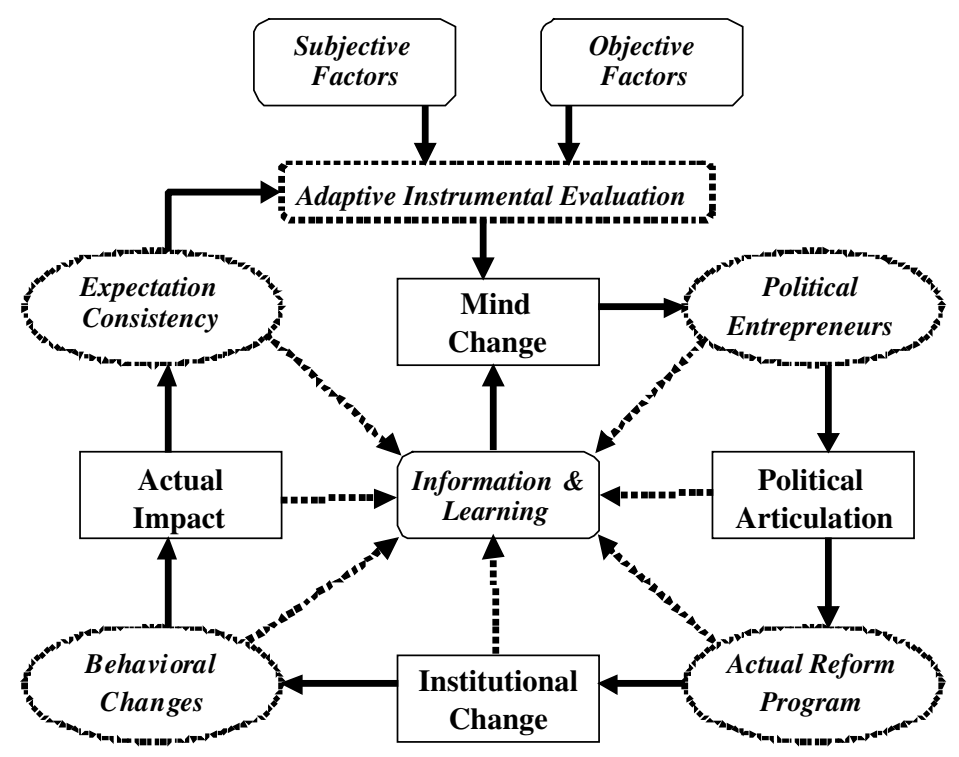

Fig. 3. A stage-based conception of the change process. Source: Saleth \& Dinar (2004).

intentional institutional design, induced institutional innovation, rent-seeking and political bargaining also have limitations as they capture only a part but not the entire process of institutional change. However, a combination of relevant theories can be logically linked to capture the whole dynamics of the change process. The stage-based perspective of institutional change proposed by Saleth \& Dinar (2004) can be a general framework for linking different theories to provide a simple but relatively more complete description of the change process. Fig. 3 depicts the stage-based perspective characterized by four main stages of institutional change. These stages progress as a circular process that is subject to constant subjective and objective feedback, learning and adaptation. In different stages, the change process is mediated by mechanisms such as instrumental (or reference point-based) subjective evaluation, information flow and learning externalities, political lobbying and bargaining, organizational power and politics, and behavioral changes and performance expectations.

Despite a fair amount of simplification of the specifics and time dimensions of the change process, Fig. 3 is able to highlight the roles that some of the key factors play in different stages. Of the four stages, the first stage involving mind change assumes a critical significance. Mind change and perceptive convergence occur among individuals not only from their adaptive and instrumental evaluation of subjective and objective factors but also from the information feedback and learning experience they gain from existing institutions and ongoing changes. Since perceptive convergence means an implicit demand for institutional change, political entrepreneurs with an eye on electoral payoffs articulate such demand with their campaigns and lobbying. ${ }^{8}$ In the second stage, political agreement about the need for change does not mean agreement about the details of

\footnotetext{
${ }^{8}$ Whether political entrepreneurs take these initiatives (a form of public goods) depends on their ex-ante perception of a tangible political benefit for them or for their political parties (Knight \& Sened, 1995).
} 
change. Owing to the potential for divergence in the transaction cost calculus of different social and political groups, there will be an intense debate, bargaining and even, counter-campaigns. The reform program that would emerge from this process is an outcome of the relative bargaining power of different groups.

The third stage is crucial as it is found where institutional supply occurs with reform implementation. But there is a vast scope for slippage between reform implementation and actual changes in view of many financial, organizational and bureaucratic constraints. Often, implementation proceeds with ceremonial and procedural changes (e.g. policy declarations and renaming or merging of organizations) and ends up only with euphoria rather than with actual change. But even these cosmetic changes are useful both in realigning political groups and in creating a pro-reform atmosphere conducive for undertaking substantive changes (e.g. legal reforms, devolution, privatization and water rights). But even with substantive institutional changes, reform benefits may not be that immediate and perceptible, as the direct outcome of institutional change is only a process of behavioral changes and its final outcome depends on the impact of these behavioral changes on actual resource allocation, use and management. While institutional change is a slow and continuous process, it is neither linear nor unidirectional, as the change process can proceed to the next stage, stay in the same stage, or revert to previous ones as dictated by the interplay of factors in different stages.

The stage-based perspective can be used as a framework to identify and link relevant theories, which can explain the dynamics in different stages of the change process. Since no theory exists to explain the process in the first stage, Saleth \& Dinar (2004) have proposed a subjective theory of institutional change. ${ }^{9}$ The process in other stages can be easily explained by a straightforward extension of available theories. For instance, the process in the second stage can be explained in terms of bargaining theories including the political economy theory of rent-seeking and interest group politics as well as the game theories based on multilateral bargaining and non-cooperative approaches. Similarly, the theory of intentional institution design and contractarian approaches can be used to explain the process of reform formulation and its political transaction. Similarly, the process in the reform implementation stage can be explained in terms of organizational and bureaucracy theories. The interface between the third and fourth stages can be explained in terms of the induced institutional innovation theory. The theory of collective action and self-building of institutions can shed light on the process of institutional evaluation and adaptation at the local level. Given the dominant players at different stages, it is also clear how and by whom the transaction costs are reckoned during the reform process. ${ }^{10}$ In this sense, the stage-based approach helps to link relevant theories coherently to explain the dynamics in different stages of institutional change.

\footnotetext{
${ }^{9}$ This theory views "perception" as an information processing mechanism and "instrumental valuation" as a decisionmaking tool. It is developed using the notions of "subjective model" (North, 1990a), "collective attitude" (Bromley, 1989b), "adaptive instrumental evaluation" (Tool, 1977; Bromley, 1985) and "mental accounting" (Kahneman \& Tversky, 1984).

${ }^{10}$ The calculations are performed mostly in an ex-ante context both by individuals and groups in evaluating different reform aspects in different stages. They lead to perceptional convergence among stakeholders, lobbying decisions of political entrepreneurs, choice and priority of reform components by policy-makers and the tactics and strategies of implementation by bureaucrats.
} 


\section{Water institutional reforms: tactics and strategies}

The major upshot from the stage-based perspective of institutional change is that the change process is not entirely evolutionary or autonomous. Deliberate and purposive policies can substantially alter or reinforce the course of institutional change. In fact, various policy options and reform strategies are implicit not only in the institutional features but also in the very mechanics of the stage-based process of institutional change itself. Saleth \& Dinar (2004) have used this as a basis for developing strategies and tactics for altering the change process in terms of a few reform design and implementation principles. For instance, the structural and sequential linkages between institutional components become the basis for developing reform design principles such as institutional prioritization, sequencing and packaging. These principles have the ability to minimize transaction costs, counter political opposition and exploit synergies from both within and outside water institutions. Thus, institutional prioritization enables us to target reform efforts and investments on those components having a high probability of success, immediate performance returns and downstream reform facilitation.

Similarly, there is also a vast scope for minimizing transaction costs with alternative sequencing and packaging of reform components. For instance, the sequential linkages between institutional aspects (e.g. user organization, cost recovery, water rights, accountability and conflict resolution) can be used to enhance the prospects for upstream and downstream institutional changes by exploiting the scale economy benefits and path dependency properties. Sequencing can also be used to phase reform across sectors (irrigation, urban supply and rural supply) and regions (as defined in terms of development status, water scarcity and reform prospects). Reform packaging (e.g. linking price revisions with system improvements or quantity assurance; packaging reforms within an investment program) also have similar effects. From a still broader perspective, water-sector reforms can themselves be packaged as part of larger macroeconomic and political reform programs.

The reform implementation principles can be used to decide how and when to initiate and deepen the reform efforts. Although reform design aspects themselves have a major bearing on these decisions, what is more important are the strategic and tactical opportunities for reform implementation provided by the exogenous factors. For instance, the political economy contexts provided by changes in the overall institutional environment (e.g. fiscal crisis, political reforms, international agreements and donor pressures) can be exploited with appropriate timing, dose and scale of reform implementation. Thus, fiscal crisis provides a favorable context for implementing even a radical program with the least political opposition. Similarly, when the water sector reform forms part of larger political or economic reforms, its implementation becomes easier owing to synergic effects and scale economy benefits from the larger program. Donor pressures and international commitments can also promote reforms that are otherwise politically difficult. ${ }^{11}$ Interestingly, the reform design aspects also have a strategic role in relaxing political economy constraints. For instance, institutional sequencing (e.g. undertaking first the politically easier

\footnotetext{
${ }^{11}$ Donor pressures can cut both ways as they are used as much to promote reforms (e.g. India) as to derail the reform proposals (e.g. Sri Lanka). Instances of the way international agreements can affect reform implementation are the Water Framework Directive in the European Union and the provisions related to subsidies from the World Trade Organization.
} 
reforms) and packaging (e.g. combining reform options favoring different groups) can bypass political opposition by creating a pro-reform climate and cementing pro-reform coalitions (see White, 1990; Haggard \& Webb, 1994). Within the stage-based process of institutional change, these roles are critical for sustaining the change process, especially during the second and third stages.

\section{Reform theories and country experiences}

The stage is now set for reflecting on the theoretical approaches and policy prescriptions discussed above in the light of existing literature and country reform experiences. Such a reflection will be focused on the following issues. How consistent is the overall approach with those in existing literature on institutional economics? Is it possible to generalize the theoretical framework to evaluate institutional change at different levels and scales? Are the hypotheses and postulates reflected in the actual reform experiences of countries? Specifically, how useful is the transaction cost framework in understanding the configuration and relative importance of various factors affecting water institutional reforms? Do the observed reform processes resemble the stage-based perspective of institutional change? Is there any evidence for practical reliance on the reform design and implementation principles? We address these and related questions based on an interpretative overview and synthesis of all the papers that are included in this special issue.

The paper by Livingston deals with the theoretical and methodological aspects of explaining and evaluating institutional change from different perspectives and at various levels. Having considered the role of economic and political concepts as well as that of the institutional economics theories, Livingston suggests that the approach of Saleth \& Dinar (2004) can be generalized to evaluate institutional change at various scales with suitable adjustments and extensions. Political economy theories and transaction cost approaches are useful to indicate the rationale for reforms. However, from the perspective of designing and implementing purposive reform policies, the stage-based perspective of the change process is considered to be more promising in view of its insights into how and when to intervene within the change process. Livingston also underlines the fact that subjective factors such as perception and ideology are as important as objective factors such as prices and economic gains for explaining institutional change. Similarly, technical features like path dependency and institutional nestedness/complementarity are also important from the perspective of both institutional transaction and performance. Livingston also supports these facts with anecdotal evidence from country experiences.

The remaining six papers present a review of the general setting of the water sector and the overall process of water institutional reforms observed in country-specific contexts. Table 1 shows the physical, socio-economic and political settings of the water sector in these countries. Although the countries considered here are only a few, they represent different continents, climatic conditions, water use patterns, development status, political arrangements and, more importantly, reform stages and coverage. Since these countries can represent many others with similar physical, socio-economic and political profiles, their reform experiences can be a basis for understanding the status and patterns of water institutional reforms observed at the global level. From the perspectives of the institutional and political economy theories of institutional reforms, the reform processes observed in the sample countries can also provide valuable evidence as well as caveats for 
Table 1. Socio-economic profile and water sector features of sample countries.

\begin{tabular}{|c|c|c|c|c|c|c|c|}
\hline \multirow[b]{2}{*}{ Particulars $^{\mathrm{a}}$} & \multirow[b]{2}{*}{ Years } & \multicolumn{6}{|c|}{ Sample countries } \\
\hline & & Australia & Chile & Morocco & Namibia & South Africa & Sri Lanka \\
\hline Political regime ${ }^{\mathrm{b}}$ & & 3 & 1 & 4 & 1 & 1 & 2 \\
\hline \multicolumn{8}{|l|}{ Population } \\
\hline Total (million) & (1999) & 19 & 15 & 28 & 2 & 42 & 19 \\
\hline Urban $(\%)$ & & 85 & 85 & 55 & 30 & 52 & 23 \\
\hline Rainfall/year $(\mathrm{cm})$ & $(2000)$ & $13-127$ & $5-125$ & $13-76$ & $5-70$ & $5-135$ & $30-234$ \\
\hline \multicolumn{8}{|l|}{ Annual water withdrawal } \\
\hline Total (bcum) & Various years & 15.1 & 21.4 & 11.1 & 0.3 & 13.3 & 9.8 \\
\hline$\%$ of total resources & & 4.2 & 4.5 & 36.7 & 0.5 & 26.2 & 22.1 \\
\hline Used for irrigation (\%) & & 33 & 84 & 92 & 68 & 72 & 96 \\
\hline \multicolumn{8}{|l|}{ Net irrigated area } \\
\hline Total (mha) & (1994-97) & 2.4 & 2.16 & 1.13 & 0.01 & 1.16 & 0.28 \\
\hline$\%$ of arable land & & 5.1 & 54.3 & 13.1 & 0.9 & 7.9 & 30.7 \\
\hline Hydropower & (1998) & 68 & 18 & 92.2 & 0 & 3 & 71 \\
\hline GNP/capita ('000\$) & (1999) & 22.45 & 8.37 & 3.19 & 5.37 & 8.32 & 3.06 \\
\hline Urbanization $(\%)$ & (1999) & 85 & 85 & 55 & 30 & 52 & 23 \\
\hline$\%$ of poor people & (1996-99) & - & 17 & 19 & - & - & 25 \\
\hline
\end{tabular}

${ }^{\mathrm{a}}$ bcum $=$ billion cubic metres or one cubic kilometre, $\mathrm{mha}=$ million hectares, and "-" means data not available

${ }^{\mathrm{b}}$ Republic $=1$; Republic with proportional representation $=2$; Federal parliamentary system $=3$; Constitutional monarchy $=4$

Sources: Gleick (1998); Seckler et al. (1998); World Bank (2003); World Resources Institute (1999)

some of the theoretical postulates and reform principles reported in the literature on institutional economics in general and water institutional economics in particular (e.g. North, 1990; Dinar, 2000; Saleth \& Dinar, 2004).

\subsection{Configurations of factors behind the reform process}

The configuration and the relative importance of factors behind the reform process can be identified by diagnostic use of the institutional transaction cost framework. Table 2 presents the results in terms of some of the major factors for each of the six sample countries. The identification

Table 2. Configuration and role of factors behind water institutional reforms.

\begin{tabular}{lcccccc}
\hline Particulars & Australia & Chile & Morocco & Namibia & South Africa & Sri Lanka \\
\hline Water scarcity/conflicts & $* *$ & $*$ & $* *$ & $* *$ & $* *$ & $*$ \\
Financial crisis & $*$ & $* *$ & $* *$ & $* * *$ & $*$ & $* * *$ \\
Draughts/salinity & $* * *$ & - & $* * *$ & $*$ & $-*$ & - \\
Macro economic reforms & $* * *$ & $* *$ & $* * *$ & - & $* *$ & $* *$ \\
Political reforms & - & $* * *$ & - & $* *$ & $*$ \\
Social issues & $*$ & - & $* *$ & $*$ & - & $* *$ \\
Donor pressures & - & $*$ & $-* *$ & $*$ & - \\
Internal/external agreements & $* *$ & - & - & $*$ & $*$ \\
Institutional synergy/pressures & $* *$ & $* *$ & $*$ & $*$ & $*$ \\
\hline
\end{tabular}

The number of *s signifies the relative importance of the factors in the context of each country. "_" means the aspect in question is "not applicable" or "not evaluated" 
of both the factors and their relative importance is based on our subjective interpretation of the way they are described in country case studies. With this, let us first interpret the transaction cost role of these factors within each country.

The legal and institutional history of the Australian water sector clearly shows the changing configuration of exogenous and endogenous factors underlying water institutional evolution over the years (McKay). However, in the case of water institutional reforms initiated since the early 1990s, the opportunity cost implications of endogenous factors (e.g. water scarcity, inter-sectoral conflicts, salinity and financial challenges from an aging water infrastructure) have become more forceful. But the factors providing the immediate political economy prompt for reform came from the macroeconomic adjustments required by the programs of fiscal federalism and economic modernization. Water sector reforms were directly linked to the National Competition Policy and tied with fiscal incentives based on an agreement between the federal and state governments within the Council of Australian Governments. Besides, social issues, especially those related to native water titles, have also provided additional support for reforms. It is this favorable climate both within and outside the water sector that explains why the reform process in Australia has been relatively smooth and fast compared to that in other countries.

In Chile, the most basic reforms in water institutions have occurred as part of the political changes during the 1980s when the new Constitution of 1980 and the Water Code of 1981 were adopted. The major driving force for these initial reforms was the ideological orientation of the military government of the 1980s (Hearne and Donoso). In recent years, however, fiscal and macroeconomic necessities are adding more pressures for reforms within water sector. Although the reform efforts were formally focused on the urban sector, autonomous and second-round institutional changes such as the emergence of water markets and refinement of water rights to deal with third-party effects and discourage speculation are becoming very significant. As these later changes signify the synergetic effects of earlier reforms, the endogenous factors such as institutional linkages and pressures are now emerging as very important forces for institutional change. Unfortunately, the path dependency effects of the political principle of proportional representation introduced by the 1980 Constitution remain a major constraint for any substantive reforms, as this principle tends more to preserve the status quo. As a result, although future changes in water institutions will be directed by economic and market requirements, they tend to be only marginal and gradual, evolving mostly within the boundaries set by the 1981 Water Code (Hearne and Donoso).

The teleological analysis of water institutional changes in Morocco shows the changing configuration of factors underlying water institutional reforms in different historical periods. Unlike the past where religious factors and colonial requirements explained the change process, in recent years, the reforms have been driven by social, economic and political factors (Doukkali). The near-exhaustion of freshwater development potential and the socio-economic implications of water scarcity have continued to generate the pressures for reform from below. But from a political economy perspective, the major fillip for reform came from the macroeconomic crisis of 1983, which occurred especially in the midst of successive droughts during 198-85. Added to this is also a dose of donor pressures, especially from the World Bank. In fact, Morocco has exploited well the political contexts of water and economic crises and the opportunities provided by the path dependency effects of existing institutions and earlier reforms. In this sense, the reform experience of Morocco also provides instances for the strategic and transaction cost implications of institutional linkages both within and outside the water sector. 
Although water institutional reforms in Namibia are only in their early stages, most of the substantive reforms are linked to the economic and political reorganization following the country's independence in 1990 (Heyns). As a result, social and political factors have played the most dominant role in reform transactions. Nevertheless, endogenous factors such as resource scarcity and financial crisis, as well as water-related exogenous aspects such as droughts and transboundary water sharing agreements have also remained the underlying forces for change (Heyns). While the reforms led to a new national water policy in 2003, draft water legislation and significant reorganization of national water administration, their effectiveness at the implementation stage is severely limited by a general lack of skills and capacity required to meet the new institutional challenges. Unfortunately, Namibia faces difficulty in building key skills and capacity as its limited resources are to be deployed in meeting the pressing need for additional water supply rather than being invested in the strategically important, but implicit necessities of developing the human side of reform management (Heyns).

Throughout the entire history of South Africa, the institutional arrangements governing its water sector have been shaped mostly by natural events such as droughts and political events such as regional unification and national elections (Backeberg). But the reform initiated since 1994 has acquired an entirely new dimension, not only because of its intensity and depth but also because of its being part of a countrywide reform program for social, economic and political reconstruction. Although the reform process was influenced by other factors that are both internal and external to the water sector, the program for national reconstruction is the most dominant factor that explains the speed and ease with which water institutional reforms were transacted in South Africa. With the initiation of the legal, policy and organizational changes, there are also now conditions for endogenous but autonomous pressures for change such as the emergence of water trading, pricing reforms and user participation in system and basin-level management (Backeberg). The South African experience suggests the strategic roles of both reform timing as well as the linkages between the induced process of macro reforms and the autonomous pressure for institutional adaptation at the local level.

The institutional changes in the water sector of Sri Lanka are not as extensive and substantive as in the other countries of our sample. But still the reform experience of this country provides interesting insights and lessons on the theory and practice of water institutional reforms. Water institutional reforms in Sri Lanka display two distinct phases, each of which was governed by two somewhat different configurations of endogenous and exogenous factors (Samad). The reforms undertaken during the 1980s, which were focused more on micro aspects such as irrigation management transfer and cost recovery, were motivated mainly by the macroeconomic crisis of the late 1980s and its fiscal fallout on the water sector. Donors, funding agencies and international technical organizations also had an influence on reform formulation and implementation, but mainly through their role in general guidance and tactical complementarity. The reforms proposed during the 1990s, on the other hand, were targeted almost exclusively on the macro aspects and were prepared essentially by expatriate consultants funded by donor agencies, especially in a changed political environment marked by extreme partisan tendencies. While the reform proposals are clearly consistent with the changing water sector requirements of the country, the manner and conditions with which they were put forward have risked their political economy prospects. This means that reform prospects depend more on strategic and political economy aspects than on technical consistency. 
Table 3. Relevance of theoretical postulates and reliance on reform principles.

\begin{tabular}{|c|c|c|c|c|c|c|}
\hline Particulars & Australia & Chile & Morocco & Namibia & South Africa & Sri Lanka \\
\hline Reform stage & $3-4$ & $3-4$ & $2-3$ & 2 & 3 & 1 \\
\hline Intensity of reforms & 4 & 3 & 3 & 2 & 4 & 1 \\
\hline Perception/pressures & 2 & - & - & - & 3 & 3 \\
\hline Political bargaining & 3 & - & - & - & 2 & 1 \\
\hline Reform packaging & 3 & - & 2 & 1 & 3 & 1 \\
\hline Reform sequencing & 3 & 2 & 2 & - & 2 & - \\
\hline Reform timing & 4 & - & 2 & 2 & 4 & - \\
\hline Reform scale/coverage & 4 & 3 & 3 & 2 & 4 & 1 \\
\hline Scope for scale economies & 4 & 3 & 2 & - & 3 & - \\
\hline
\end{tabular}

All numbers, except those related to the reform stage, are on a scale of 1-5 with an increasing level of importance or significance. The values are based on our own interpretation of the analysis of the aspects as reported by the authors of country case studies. "-" means the aspect in question is "not applicable" or "not evaluated".

\subsection{Evidence for theoretical postulates and reform principles}

The country reform experience also provides some interesting anecdotal evidence for some important theoretical postulates and reform principles. The previous section clearly demonstrates the way the institutional transaction theory can be used as a diagnostic framework for gaining insight into the configuration and relative significance of factors behind the reform initiation and implementation process. The emphasis was on the role of timing as well as on the strategic use of the external context and internal dynamics of the reform process. Table 3 summarizes the evidence for the practical relevance of a few important theoretical postulates and the actual reliance on reform design and implementation principles as observed in our sample countries. To facilitate a comparative perspective, the relative relevance of and reliance on these aspects is evaluated and presented using a scale of $1-5$. This evaluation, as well as the description of the reform stage for the countries, is based on our own interpretation of the evidence provided in country case studies as analyzed in the remainder of the section.

Utilizing the stage-based framework of institutional change and the description of water institutional reforms provided in country case studies, it is possible to characterize the stage in which the reform process of each country is positioned. For instance, the reform process in Sri Lanka is only at its initial stage. Although a generic outline of the reform program is available and has caused an intense political debate, it is yet to attain a clear consensus and a political articulation. The country has undertaken some notable reforms during the 1980s in irrigation management transfer and cost recovery, in all fairness, but these changes have neither been permanent nor effective as they were undertaken in an economic and institutional vacuum. The reform process in Namibia, on the other hand, can be placed in the second stage because the country has already made significant advances on the policy and organizational fronts. But the task of taking the process to the next stage still remains a major challenge owing to financial and capacity constraints for reform implementation and consolidation.

Morocco was able to pass a new water law and achieve significant progress in key areas such as privatization of urban water supply, public-private partnership in the irrigation sector, user participation and irrigation water pricing. This is more appropriate in characterizing the reform process of this country as being in the midcourse between the second and third stages. The reform 
process in South Africa can be correctly placed in the third stage as the country has already created a modern legal and policy framework with commensurate changes in national water organizations. Progress on issues such as water rights, user organizations and cost recovery has also been notable. But the local adaptation of community adjustment to the new changes is still only in an evolving stage. In contrast, the reform process both in Australia and Chile can be placed between the third and fourth stages of the reform process, as implementation has been extensive and effective enough to generate observed improvements in water use efficiency and sector performance. But the process in both countries will have to still proceed on higher level cycles of change in order to enhance and sustain these benefits under constantly changing economic and resource realities.

There is an obvious correspondence between the reform stage and reform intensity observed across the sample countries. Generally, the reform intensity is relatively high in countries either approaching or passing through the third stage, in which politically accepted reform programs are being implemented. Thus, the extent and intensity of reforms are the lowest in Sri Lanka, whereas they are the highest in Australia and South Africa. They are, however, significant in Namibia, but more substantial in Chile and Morocco. In fairness, it should be noted that from an overall perspective, the recent reforms in Chile are not as extensive as those in Morocco, South Africa or Australia. However, since Chile undertook some of the most fundamental changes during the 1980s, the recent changes are mostly in the form of adaptations of and refinements to the already existing institutional arrangements as a response to changing economic conditions and secondgeneration institutional demands. Nevertheless, these changes, especially the refinements in water rights systems, are quite effective.

The reform experiences of the six countries do provide evidence for the role of public perception and grassroots pressures during the reform process. This evidence is not only direct and obvious but also implicit and subtle. The most notable instance of direct evidence is the institutional changes brought about in Australia in the aftermath of public outcry over the Sydney water quality crisis of 1998 (McKay). Although the quality problem is not that serious, the media campaign and public outcry over the issue led the New South Wales government to move the catchment management and raw water delivery functions from the Sydney Waters to a newly created organizational entity. Sri Lanka provides another instance of how the media campaign and public protest have led to the delay and eventual withdrawal of a water policy document. This is a case of how reform opponents have succeeded using a deliberate distortion of genuine issues such as water rights and private sector participation by linking them to the idea of a corporate and external plot to control water resources (Samad). It is also a case of public relations failure as reform proponents were unable to keep the public focus on the plus side of reforms.

Although the short-term swings in pubic opinion, as depicted by the Australian and Sri Lankan instances, can be effective both in facilitating and constraining changes, what is more important from the perspective of the change process is the long-term evolution and convergence in stakeholders' perception. Instances of such subtle roles in perceptive convergence can be seen in all countries that have substantial reforms such as Australia, South Africa, Chile, Morocco and Namibia. Such subtle evidence is clear because it is impossible to explain the political consensus for reforms and their implementation without recognizing the underlying perceptive convergence of both the communities and policymakers. While the similarity of subjective evaluation of objective realities leads to perceptive convergence, the political process also mediates and shapes such convergence through political debate and bargaining. In this case, perceptive convergence among 
stakeholders creates the demand for institutional change whereas the political convergence among interest groups becomes the basis for the supply of institutional change.

The country case studies also provide some evidence for the role of political bargaining, especially in the case of Australia, South Africa and Sri Lanka. Unlike South Africa and Sri Lanka, where the bargaining was among different political and social groups, in Australia it was between the federal and state governments covering issues such as the nature, coverage, time frame and incentive requirements of the reform program. While the bargaining process in the case of Australia and South Africa has led to reforms with necessary political and tactical adjustments, in Sri Lanka the process has blocked the reform by delay and eventual, though temporary, withdrawal of the reform program itself. The political economy of water sector reforms in Sri Lanka also suggests that a political system with proportional representation can be less conducive to reform because the system often leads to a limited mandate and political power for the majority party. Under this condition, the prospects for reform, especially those aiming at radical changes, will be very dim unless there is a very high degree of public pressure, political consensus, or heavy pressures from funding agencies. Although this condition also applies to Chile where the proportional representation system was introduced after the 1980 Constitution, fortunately, the country could complete some of the most fundamental institutional changes under an ideologically driven military government during the early 1980s. Reform formulation and implementation also remain an uphill task in other countries with multiparty democracy and coalitional governments.

The country case studies provide some interesting evidence for the use of reform design and implementation principles such as reform packaging, sequencing, timing and scale/coverage. For instance, the effectiveness of water sector reforms in South Africa can be explained both in terms of their being part of a countrywide economic and political reform program as well as in terms of their timing to coincide with the development of a broad-based political system (Backeberg). This fact also applies to Australia where water sector reforms were packaged with financial incentives from the federal government and concerted with national economic reforms under the National Competition Policy (McKay). Although Namibia could combine water sector reform with the post-colonial reconstruction of the country, it was not as successful as South Africa partly owing to the ad hoc approach and limited scale of reforms and partly owing to the absence of several factors including political commitment, resources allocation and technical capacity (Heyns). The Namibia case adds an important caveat, as reform timing can be effective only with certain political, financial and technical preconditions.

Apart from the evidence for the packaging of water sector reform as a whole with other reform programs, there is also evidence for the packaging of individual reform components within the water sector reform program itself. For instance, in Morocco, the policy of promoting groundwater irrigation has been effective because it was coupled with a waiver for well-digging authorization and subsidies for groundwater investment. In contrast, the policy of crop pattern liberalization has remained ineffective as it lacked concurrent changes in water distribution rules, marketing arrangements and extension systems (Doukkali). In South Africa, in addition to the linkages between water institutional reforms and agricultural reforms, there are also linkages between irrigation management transfer and cost recovery policies (Backeberg). In Sri Lanka, the relative effectiveness of the reforms during the 1980s that focused on irrigation management transfer can be explained essentially by the fact that such reforms were packaged as a larger donorfunded program for irrigation improvement and agricultural development. By the same token, the 
lack of such a packaging approach has been the major problem with the macro institutional reforms proposed during the 1990s (Samad). Chile provides another interesting kind of packaging where the corporatization and privatization of urban water utilities were pursued with the special policy of targeted subsidy for poor users (Hearne and Donoso).

Reform sequencing is also pervasive among the six sample countries. In general terms, since most of the reforms being planned and undertaken in Australia and Chile are in the form of adjustments to and reorientation of, an already existing set of institutional arrangements, they are structurally and sequentially linked to the earlier reform programs. Thus, water rights reforms to account for third-party effects in Chile or to tackle regional and environmental water allocation in Australia are linked to the prior establishment of water rights in both cases (Hearne and Donoso). Similarly, it is the existence of volumetric water rights that has led to the Cap program that aims to reduce current water withdrawals back to the 1994 level in the Murray-Darling River Basin of Australia. The same institutional condition has also facilitated other downstream reforms such as the privatization of irrigation supply in New South Wales and corporatization in Victoria (McKay). In Chile, urban water sector reforms were quite successful because market incentives and regulation were established much before the water supply infrastructure and assets were transferred to the newly created urban water utilities (Hearne and Donoso). Path dependency and reform sequencing have also remained as robust factors during the reform process in Morocco. Here, sequencing can be seen both in the sectoral focus of reforms - as irrigation reforms occurred after the consolidation of urban sector reforms - as well as in the regional focus - as areas under larger-scale public irrigation have undergone reforms far ahead of those under privately managed and groundwaterbased irrigation sector (Doukkali). In the case of both Morocco and South Africa, there was also some sequencing as the reform components such as the legal and policy reforms at the national level preceded the organizational reforms, especially those at the regional and local levels. The reverse has happened in Sri Lanka as simple reorganization or renaming of water organizations occurs without much progress on the legal and policy fronts (Samad).

What is more important to note here are the roles that reform design and implementation principles play in relaxing the political economy constraints, exploiting institutional synergy to facilitate downstream reforms and catalyzing reform transaction. These roles are illustrated by the reform experiences of all the sample countries in varying formats and degrees. In general terms, the ease with which reforms are being implemented in Australia and Chile, both with a relatively matured water institutional arrangement, or the difficulty being faced in countries such as Sri Lanka within incipient institutional setting, shows how important the path dependency properties are in shaping the nature and intensity of institutional reforms. In addition to the roles of reform packaging and sequencing, reform scale is also important for generating scale economy effects as well as in precluding the consolidation of opposing forces for reforms. However, the choice of reform scale is also conditioned by institutional and political economy contexts. ${ }^{12}$ The

\footnotetext{
${ }^{12}$ In institutional contexts that are politically not that divisive (e.g. irrigation management transfer) and in political contexts with crisis events (e.g. Mexico in the aftermath of the macro economic crisis of the early 1980s and Morocco during the severe droughts of the early 1980s), or with ideologically committed governments (e.g. Chile under the military government during the 1980s), it is easy to have large- scale reforms causing "big bang" effects. In other cases, the reform scale depends heavily on the prevailing political configurations. In these cases, a smaller but a sequentially linked and well-timed program has a greater prospect of success.
} 
experience of South Africa demonstrates the effects of scale both in reducing the transaction costs and in enhancing the effectiveness of implementation. While the South Africa case shows the effects of scale in terms of the extent and coverage of currently implemented reforms, the Australia and Chile experiences illustrate the effects of scale in terms of structural linkages of currently implemented reforms to the earlier reforms. From an overall perspective, among our sample countries, the scope for scale economy effects is very high in Australia and South Africa and remains quite substantial in Chile and Morocco.

\section{Conclusions and implications for theory and policy}

In its attempt to provide a sound background and context for the papers included in this special section, this paper provides an outline of the conceptual, analytical and theoretical aspects of water institutional reforms and a synthesis of the main findings from the reform experiences of six countries: Australia, Chile, Morocco, Namibia, South Africa and Sri Lanka. The paper relies on some of the latest theoretical and empirical developments on the subject. It presents an analytical framework for unbundling water institutions to show their endogenous and exogenous linkages; a transaction cost approach as a diagnostic tool for understanding the role of various factors affecting water institutions; and a stage-based perspective to provide insights into the internal mechanics and dynamics inherent in the process of institutional change both in general and in water sector contexts. Although these analytical and theoretical frameworks are presented here by considering the macro and formal segments of water institutions, they can be generalized for application in basin, regional and local contexts as well. The intuitive way in which the structure and environment of water institutions and the sources and dynamics of their change are presented here is very useful for dispelling the conceptual ambiguity and policy distortions currently constraining reforms in many situations.

From the perspective of reform policy, the endogenous and exogenous features of institutions considered within the transaction cost framework are valuable for deriving reform design and implementation principles as they have considerable tactical and strategic advantages, not only in exploiting institutional linkages and synergies but also in countering the political economy constraints for change. The transaction cost approach sheds lights on the configuration and relative importance of factors motivating institutional change in different contexts. The stagebased perspective provides insights both into how the configurations of factors vary across different stages of the change process and into what roles perception, information, learning and adaptation play during the entire process of institutional change. Since the change process is not entirely autonomous, purposeful interventions are possible, especially those based on reform design and implementation principles as specific strategies both for setting the general reform climate as well as for guiding the change process. The country-specific reform experiences presented in this special issue indeed provide considerable evidence, not only for the actual reliance on these principles but also for the relevance of theoretical postulates related to the transaction cost implications of institutional linkages, strategic role of exogenous factors and stage-specific dynamics of the reform process.

The synthesis of reform theories with country experiences attempted in this paper leads to a few stylized facts. First, although endogenous factors related to resource scarcity and sector 
performance have remained as underlying factors, the major prompt for change comes mainly from exogenous sources such as the macro economic crisis and political reforms. Second, while countries have used the strategic context of exogenous factors, this has happened more by coincidence than by design. This is also true, to a greater extent, for the reform design and implementation principles as the role of institutional linkages and synergies have not been internalized within the reform strategy in almost all cases. Third, there are fundamental links between the induced changes effected by formal reforms at the macro level and the autonomous changes occurring at the micro level. But these linkages can be more visible and effective only with a certain critical minimum level of formal changes in key institutions. Finally, ad hoc approaches to reforms, as dictated by political and financial constraints, can be counterproductive owing to the dilution of their effects and consolidation of reform opposition. In politically and fiscally constraining conditions, the best strategy is to have selective but sequentially linked reforms focused on institutional components and sectoral contexts with a better reform prospect. Here lies the critical role of strategic reform planning.

Although the demand-side role of institutional education and the supply-side role of comparative research are now being increasingly recognized, they are not yet getting the policy attention they deserve because of the mistaken view that their effects are slow, remote and marginal. But considering the fact that ambiguity in the understanding and divergence in the interpretations of institutions often constitute the initial but main stumbling blocks for institutional reforms in many contexts, the institutional roles of education and research can be immediate, substantial and indispensable. The way water institutions and their change processes are conceptualized here can be a starting point for developing institutional learning and evaluation tools to facilitate a better and consensual understanding of institutions among both the public and policy makers. Public policy in this respect is as important as the design and technical aspects of water sector reform policies. This special issue, it is hoped, can be a catalyst to generate further interest and policy debate in this new area of institutional research.

\section{Acknowledgements}

The funding support of the Agriculture and Rural Development Department of the World Bank and of the International Water Management Institute in the preparation of the papers including the present one; the continued cooperation of all the contributing authors; the review support of Carl Bauer, Michel Benoit-Cattin, Lin Crase, Nihal Fernando, Peter van Niekerk, Petr Sauer and Barbara Schreiner; the copy-editing assistance of Kingsley Kurukulasuriya; and the constant interest of Frank Rijsberman and Jerry Delli Priscoli are gratefully acknowledged. The views expressed in this paper are those of the authors and should not be attributed to the World Bank.

\section{References}

Bromley, D. W. (1985). Resources and economic development, Journal of Economic Issues, 19(September), 779-96. Bromley, D. W. (1989a). Economic Interests and Institutions: The Conceptual Foundations of Public Policy, Basil Blackwell, New York.

Bromley, D. W. (1989b). Institutional change and economic efficiency, Journal of Economic Issues, 23(3), 735-759. 
Challen, R. (2000). Institutions, Transaction Costs and Environmental Policy: Institutional Reform for Water Resources, Edward Elgar, Cheltenham, UK.

Commons, J. R. (1934). Institutional Economics, Macmillan, New York.

Commons, J. R. (1968). Legal Foundations of Capitalism, University of Wisconsin Press, Madison.

Dinar, A. (ed.) (2000). The Political Economy of Water Pricing Reforms, Oxford University Press, New York.

Douglas, M. (1986). How Institutions Think?, Syracuse University Press, New York.

Easter, K. W., Dinar, A. \& Rosegrant, M. (eds) (1998). Markets for Water: Potential and Performance, Kluwer Academic Press, Boston.

Gleick, P. H. (1998). The World's Water: The Biennial Report on Fresh Water Resources, Island Press, Washington, DC.

Gopalakrishnan, C., Biswas, A. K. \& Tortajada, C. (eds) (2004). Water Resources Management: Structure, Evolution and Performance of Water Institutions, Springer-Verlag, New York (Forthcoming).

Haggard, S. \& Webb, S. B. (1994). Introduction, Voting for Reform: Democracy, Political Liberalization and Economic Adjustment, Haggard, S. \& Webb, S. B. (eds), World Bank, Washington, DC.

Hodgson, G. M. (1998). The approach of institutional economics, Journal of Economic Literature, 36(1), $166-192$.

Kahneman, D. \& Tversky, A. (1984). Choices, values and frames, American Psychologist, 39(4), 341-350.

Knight, J. \& Sened, I. (1995). Introduction, Explaining Social Institutions, Knight J. \& Sened, I. (eds), The University of Michigan Press, Ann Arbor.

Le Moigne, G., Barghouti, S., Feder, G., Garbus, L. \& Xie, M. (eds) (1992). Country Experiences with Water Resources Management: Economic, Institutional, Technological and Environmental Issues, World Bank Technical Paper No: 175, World Bank, Washington, DC.

North, D. C. (1990a). Institutions, Institutional Change and Economic Performance, Cambridge University Press, Cambridge, MA.

North, D. C. (1990b). A transaction cost theory of politics, Journal of Theoretical Politics, 2(4), 355-367.

Ostrom, E. (1990). Governing the Commons: The Evolution of Institutions for Collective Action, Cambridge University Press, Cambridge, UK.

Ostrom, E. (1999). Institutional Rational Choice: An Assessment of the Institutional Analysis and Development Framework, Working Paper, Workshop in Political Theory and Policy Analysis, Indiana University, Bloomington.

Saleth, R. M. \& Dinar, A. (1999). Water Challenge and Institutional Response: A Cross-Country Perspective, World Bank Policy Research Working Paper No: 2045, World Bank, Washington, DC.

Saleth, R. M. \& Dinar, A. (2000). Institutional changes in global water sector: trends, patterns and implications, Water Policy, 2(3), 175-199.

Saleth, R. M. \& Dinar, A. (2004). The Institutional Economics of Water: A Cross-Country Analysis of Institutions and Performance, Edward Elgar, Cheltenham, UK.

Savedoff, W. \& Spiller, P. (eds) (1999). Spilled Water: Institutional Commitment in the Provision of Water Services, InterAmerican Development Bank, Washington, DC.

Seckler, D., Amarasinghe, U., Molden, D., de Silva, R. \& Barker, R. (1998). World Water Demand and Supply, 1990 to 2025: Scenarios and Issues, Research Report, International Water Management Institute, Colombo, Sri Lanka.

Shirley, M. (ed.) (2002). Thirsting for Efficiency: The Economics and Politics of Urban Water System Reform, Elsevier Science, Amsterdam.

Stein, J. (1997). How institutions learn: a socio-cognitive perspective, Journal of Economic Issues, 31(3), 729-39.

Tool, M. R. (1977). A social value theory in neo-institutional economics, Journal of Economic Issues, 11(December), 823-849.

Veblen, T. B. (1919). The Place of Science in Modern Civilization and Other Essays, Huebsch, New York.

Vermillion, D. L. (1997). Impact of Irrigation Management Transfer: A Review of Evidence, Research Report, International Water Management Institute, Colombo.

White, L. G. (1990). Implementing Policy Reforms in LDCs: A Strategy for Designing and Effecting Change, Lynne Rienner Publishers Boulder \& London.

Williamson, O. E. (1985). The Economic Institutions of Capitalism: Firms, Markets and Relational Contracting, Free Press, New York.

World Bank (2003). World Development Report: 2003. World Bank, Washington, DC.

World Resources Institute (1999). World Resources, Washington, DC. 
